\title{
PENGGUNAAN EDMODO SEBAGAI MEDIA PEMBELAJARAN MATEMATIKA
}

\author{
Vera Dewi Kartini Ompusunggu ${ }^{1)}$ Nilam Sari ${ }^{2)}$ \\ FKIP, Universitas Quality \\ email: nasranidua_ompusunggu@yahoo.com
}

\begin{abstract}
Abstrak
Seiring dengan pesatnya perkembangan zaman, seluruh aspek kehidupanpun ikut berubah. Hal ini merupakan sebuah tantangan untuk para pendidik agar dapat menggunakan teknologi secara optimal dan dapat memudahkan interaksi dengan peserta didik dalam proses belajar mengajar salah satunya adalah edmodo. Edmodo adalah sebuah platform pembelajaran sosial untuk guru/dosen dan siswa/mahasiswa yang menyediakan beberapa fitur untuk mendukung e-learning seperti penugasan, kuis, penilaian, dan lain sebagainya. Melalui edmodo guru dan siswa dapat berbagi catatan dan dokumen serta dapat melanjutkan diskusi secara online. Penelitian ini bertujuan untuk mendeskripsikan penggunaan edmodo dalam pembelajaran geometri analitik pada mahasiswa semester 4 prodi Pendidikan Matematika Universitas Quality, Medan. Penelitian ini merupakan penelitian kualitatif. Dikatakan penelitian kualitatif karena bersifat deskriptif dan cenderung menggunakan analisis terhadap subjek penelitian yang ditonjolkan. Teknik analisis data yang digunakan adalah reduksi data, penyajian data, dan verifikasi dan penarikan kesimpulan. Validasi data menggunakan triangulasi (gabungan). Reduksi data yakni data yang telah diperoleh direduksi sehingga memberikan gambaran yang lebih jelas dan mempermudah peneliti untuk melakukan pengumpulan data. Penyajian data dilakukan dalam bentuk uraian singkat. Verifikasi dan penarikan kesimpulan merupakan temuan yang baru yang sebelumnya belum pernah ada.
\end{abstract}

\section{Kata Kunci: Edmodo, Media}

\begin{abstract}
Along with the rapid development of the times, all aspects of life also changed. This is a challenge for educators to be able to use technology optimally and can facilitate interaction with students in the learning process, one of which is Edmodo. Edmodo is a social learning platform for teachers / lecturers and students / students that provides several features to support e-learning such as assignments, quizzes, assessments, etc. Through edmodo teachers and students can share notes and documents and can share discussions online. This study aims to describe the use of edmodo in analytic geometry learning in 5th semester students of the Mathematics Education study program at Quality University, Medan. This research is a qualitative research. Qualitative research is said because it is descriptive and tends to use analysis of research subjects that are highlighted. Analysis techniques used are reduction, presentation, and verification and conclusion. Validation using triangulation (combined). Reduction namely that has been obtained is reduced so that it gives a clearer picture and makes it easier for researchers to collect. Presentation is done in the form of brief description. Verification and drawing conclusions are new findings that have never before existed.
\end{abstract}

Keyword: Edmodo, Media 


\section{PENDAHULUAN}

Teknologi informasi dan komunikasi sekarang ini berkembang dengan sangat pesat dan cepat. Perkembangan zaman telah mempengaruhi berbagai bidang dalam kehidupan seperti teknologi, ekonomi, pendidikan, lingkungan hingga politik. Dengan berkembangnya salah satu bidang yang berperan penting bagi kemajuan hidup seseorang maka hal tersebut akan lebih mudah tercapai apabila bidang lainnya dapat menyeimbangi perkembangan di bidang teknologi. Informasi apapun dapat diakses dengan mudah di manapun dan kapanpun melalui smartphone, tablet dan laptop yang terkoneksi dengan jaringan internet. Selain teknologi, terdapat bidang lain yang ternyata memiliki peranan terpenting yaitu pendidikan. Jangan sampai dunia pendidikan tertinggal atau ditinggalkan oleh perkembangan tersebut. Dengan berpengaruhnya kedua bidang tersebut maka pendidikan dan teknologi dapat saling melengkapi, dimana pendidikan yang meliputi pembelajaran dapat di dukung dengan sesuatu yang baru misalnya dengan memanfaatkan perkembangan teknologi.

E-learning adalah suatu kemajuan penting dalam sistem pendidikan modern. E-learning ini membawa pengaruh terjadinya proses transformasi pendidikan konvensional ke dalam bentuk digital, baik secara isi (contents) maupun sistemnya. $E$ learning adalah suatu jenis belajar mengajar yang memungkinkan tersampaikannya bahan ajar ke siswa dengan menggunakan media Internet, Intranet atau media jaringan komputer lain (Setiawan 2013).

Salah satu media pembelajaran online yang telah digunakan oleh para pengajar dibanyak negara adalah Edmodo. Edmodo merupakan media sosial yang mendukung pembelajaran, dengan tampilan hampir serupa dengan facebook. Menurut Zwang (2010), "edmodo adalah sebuah situs pendidikan berbasis social networking yang di dalamnya terdapat berbagai konten untuk pendidikan. Edmodo dikembangkan pada akhir tahun 2008 oleh Nic Borg dan Jeff Ohara yang berkeyakinan bahwa perlu dikembangkan lingkungan kampus yang terhubung dengan semua aktifitas di dunia. Edmodo adalah platform media sosial yang sering digambarkan sebagai Facebook untuk kampus dan dapat berfungsi lebih banyak lagi sesuai dengan kebutuhan. "Edmodo merupakan aplikasi yang menarik bagi dosen dan mahasiswa dengan elemen sosial yang menyerupai Facebook, tapi sesungguhnya ada nilai lebih besar dalam aplikasi edukasi berbasis jejaring sosial ini" (Basori 2013)

Edmodo menyediakan cara yang aman dan mudah untuk terhubung dengan dosen dan mahasiswa lain. Melalui edmodo guru dan siswa dapat berbagi dokumen dalam bentuk buku maupun link. Weherspoon menyimpulkan bahwa Edmodo dapat dilihat sebagai sebuah Learning Management System (LMS) yang dapat memfasilitasi dosen untuk membuat dan mengatur kelas online mereka secara mudah (Witherspoon, 2011). Situs ini menyediakan cara yang sederhana bagi dosen dan mahasiswa untuk terhubung dan kerjasama secara virtual. Kemudahan akses internet yang didapat di zaman sekarang ini mempermudah koneksi antara peserta didik dengan pendidik.

Peraturan Menteri Pendidikan dan Kebudayaan Republik Indonesia Nomor 49 Tahun 2014 tentang Standar Nasional Pendidikan Tinggi pasal 14 menyebutkan bahwa proses pembelajaran melalui kegiatan kurikuler wajib menggunakan metode pembelajaran yang efektif. Efektif pada peraturan tersebut mempunyai arti bahwa proses pembelajaran harus menggunakan waktu secara optimum dan bersifat kolaboratif. Artinya, interaksi antara dosen dan mahasiswa 
harus tetap terjaga dan semua materi terinternalisasi dengan baik sesuai dengan waktu yang telah direncanakan. Kriteria yang disampaikan pada peraturan tersebut sebenarnya bisa dicapai dengan memanfaatkan produk TIK atau peran teknologi untuk mendukung proses pembelajaran di dalam kelas.

Hasil penelitian (Colin and Malcolm, 2002) dalam proses belajar mengajar mengatakan bahwa tingkat retensi peserta didik akan mencapai: membaca $20 \%$, mendengar $30 \%$, melihat $40 \%$, melakukan $60 \%$, dan melihat, mengucapkan, mendengar serta melakukan $90 \%$. Inti proses pengajaran adalah kegiatan belajar peseta didik dalam mencapai suatu tujuan pembelajaran.

Fakta di lapangan menunjukkan bahwa proses pembelajaran masih didominasi dengan cara bertatap muka secara langsung (face-to-face), seperti halnya kegiatan perkuliahan yang dilakukan di Pendidikan Matematika, Fakultas Keguruan dan Ilmu Pendidikan, Universitas Quality. Hasil observasi yang dilakukan oleh peneliti menunjukkan bahwa model pembelajaran yang dilakukan masih didominasi dengan aktivitas bertatap muka secara langsung. Teknologi sudah berperan di dalam proses pembelajarannya, namun masih belum dominan. Pembelajaran ini yang masih cenderung disebut dengan model pembelajaran konvensional karena peran teknologi masih sangat kecil. Teknologi hanya digunakan untuk mendistribusikan informasi saja, seperti Whatsapp. Survey di lapangan menujukkan bahwa pembelajaran secara konvensional memiliki kelebihan dan kekurangan.

Dalam proses pembelajaran matematika masih sangat monoton dengan hanya menggunakan buku catatan, bahan fotocopian dan buku ajar. Dosen merupakan fasilitator terpenting dalam penyampaian ilmu kepada mahasiswa harus mampu berfikir kreatif didalam menciptakan suasana pembelajaran agar ilmu yang akan ditransfer dapat diterima oleh mahasiswa dengan baik. Pada kenyataannya proses pembelajaran di kelas belum ada yang memanfaatkan media e-learning berbasis Edmodo. Berdasarkan pemaparan di atas, pengenalan, dan penggunaan media sosial Edmodo bagi mahasiswa pendidikan matematika di Universitas Quality dalam proses belajar mengajar sangatlah tepat untuk dilakukan. Keterampilan penggunaan media sosial yang dimiliki oleh mahasiswa tentu akan sangat mempermudah proses pembelajaran dengan menggunakan Edmodo yang memiliki keunggulan serupa dengan aplikasi E-Learning pada umumnya.

\section{METODE PENELITIAN}

Penelitian ini termasuk jenis penelitian kualitatif. Dikatakan penelitian kualitatif karena bersifat deskriptif dan cenderung menggunakan analisis terhadap subjek penelitian yang ditonjolkan. Menurut Sugiyono(2012) penelitian kualitatif adalah metode penelitian yang digunakan untuk meneliti pada kondisi obyek yang alamiah, dimana peneliti adalah sebagai instrument kunci. Jenis penelitian ini juga menggunakan penelitian eksperimen semu (quasy eksperiment research). Penelitian eksperimen semu (quasy eksperiment research) yaitu suatu penelitian yang dilakukan berdasarkan suatu percobaan pura-pura dimana kelompok control tidak dapat berfungsi sepenuhnya mengontrol variablevariabel luar yang mempengaruhi pelaksanaan eksperimen yang sebenarnya ("[PDF] Sugiyono Metode Penelitian Kuantitatif Kualitatif Dan r d - Free Download PDF" n.d.). Peneliti juga tidak dapat melakukan pengendalian variable secara penuh karena subjek penelitian secara alami telah terbentuk dalam suatu kelompok yang utuh, seperti kelompok mahasiswa dalam satu kelas. Rancangan penelitian 
ini menggunakan pre-test-post-test control group design. Penelitian ini membagi sasaran penelitian menjadi dua kelas sebagai sampel yaitu kelas eksperimen (Edmodo) dan kelas kontrol (konvensional) dimana power point sebagai media pembelajaran. Penelitian ini menggunakan pendekatan kuantitatif dan kualitatif dalam pengumpulan datanya, dimana pendekatan kualitatif digunakan untuk menjabarkan dan menjelaskan pembelajaran e-learning berbasis edmodo terhadap komunikasi matematika setelah dilakukannya proses pembelajaran. Penelitian ini juga menggunakan pendekatan kuantitatif dalam mengukur komunikasi mahasiswa dari ranah kognitif dengan menggunakan pre test dan post test. Pre test bertujuan untuk mengetahui kemampuan akademik awal kedua kelas sebelum mendapat perlakuan. Selanjutnya kelas eksperimen mendapat perlakuan dengan proses pembelajaran e-learning berbasis edmodo dan kelas kontrol mendapat perlakuan yang berbeda yaitu dengan proses pembelajaran konvensional yang menggunakan media pembelajaran power point. Setelah kedua kelas tersebut diberi perlakuan, kemudian dilakukan post test untuk mengetahui perbedaan komunikasi dari kelompok eksperimen dan kelompok kontrol. Penelitian campuran merupakan pendekatan penelitian yang mengkombinasikan antara penelitian kualitatif dengan penelitian kuantitatif. Menurut pendapat ("[PDF] Sugiyono Metode Penelitian Kuantitatif Kualitatif Dan r d - Free Download PDF" n.d.) menyatakan bahwa metode penelitian kombinasi (mixed methods) adalah suatu metode penelitian yang mengkombinasikan atau menggabungkan antara metode kuantitatif dengan metode kualitatif untuk digunakan secara bersama-sama dalam suatu kegiatan penelitian, sehingga diperoleh data yang lebih komperehensif, valid, reliable, dan objektif. Dalam pengumpulan datanya peneliti melakukannya secara bersamaan baik data kuantitatif yang berupa hasil belajar serta data kualitatif yang berupa aktivitas belajar.

Penelitian dilakukan pada program studi Pendidikan Matematika FKIP Universitas Quality tahun 2018, yaitu pada mata kuliah yang diampu oleh subjek penelitian. Data dalam penelitian ini diperoleh peneliti dari observasi mahasiswa dan dosen matematika khususnya yang mengajar Geometri Analitik yang memiliki akun di edmodo. Sedangkan informasi dalam penelitian ini diperoleh dari berbagai peristiwa. Peneliti melakukan observasi langsung di lapangan dalam proses belajar mengajar Geometri Analitik. Teknik analisis data yang digunakan adalah reduksi data, penyajian data, dan verifikasi dan penarikan kesimpulan. Validasi data menggunakan triangulasi (gabungan). Reduksi data yakni data yang telah diperoleh direduksi sehingga memberikan gambaran yang lebih jelas dan mempermudah peneliti untuk melakukan pengumpulan data. Penyajian data dilakukan dalam bentuk uraian singkat. Verifikasi dan penarikan kesimpulan merupakan temuan yang baru yang sebelumnya belum pernah ada. Temuan dapat berupa deskripsi atau gambaran suatu obyek yang sebelumnya masih remang-remang sehingga setelah diteliti menjadi jelas.

Dua puluh tujuh orang mahasiswa yang dipilih sebagai subjek penelitian adalah mahasiswa program studi pendidikan matematika dan belum pernah menggunakan media belajar elearning. Edmodo sebelumnya. Ke-27 mahasiswa tersebut diwajibkan untuk masuk pada group kelas online selama satu semester. Terdapat tiga macam instrumen penelitian digunakan dalam penelitian ini: buku harian (diary), questionaire, dan Edmodo. Dosen akan membuat diary mulai dari awal semester untuk menginvestigasi bagaimana dia mempelajari dan menggunakan Edmodo, termasuk bagaimana persepsinya tentang penggunaan Edmodo. Kuesioner yang 
terdiri atas lima point skala Likert menanyakan pendapat dosen tentang Edmodo dan dua pertanyaan terbuka tentang permasalahan dan saran dosen tentang Edmodo, diberikan kepada 27 mahasiswa diakhir perkuliahan. Questionare akan diberikan dengan Edmodo, dan jawaban juga akan dicatat di Edmodo untuk menguji mereka dalam menggunakan Edmodo. Data yang diperoleh dari buku harian Dosen dianalisis dan dikategorikan atas 2 groups: persiapan dan pelaksanaan pembelajaran, sementara itu data yang diambil dari Edmodo dikelompokan atas kegiatan-kegiatan yang dilakukan oleh dosen selama dalam satu semester.

\section{HASIL DAN PEMBAHASAN}

Pembelajaran Geometri Analitik dengan memanfaatkan media $e$ learning berbasis Edmodo ini dimulai dengan melakukan pembuatan grup, yang terdiri dari mahasiswa prodi Pendidikan Matematika semester 4 yang kemudian dikelompokkan berdasarkan kelasnya masing-masing yaitu kelas A dan B. Hal ini bertujuan agar pada saat dosen memberikan tugas kepada mahasiswa, tidak tercampur dengan kelas yang lain. Mahasiswa bisa saling memberikan pendapatnya pada grup tersebut. Grup yang telah dibuat merupakan sarana penyampaian materi yang diajarkan. Kemudian menambahkan anggota yang terdiri dari mahasiswa yang berada di kelas tersebut. Mahasiswa juga terlihat mereka dapat mengikuti perkuliahan elearning dengan Edmodo, hal ini terlihat dari jumlah peserta belajar yang tergabung dalam group, menyerahkan tugas, dan melaksanakan quiz dengan Edmodo. Pembelajaran dengan memanfaatkan media e-learning berbasis edmodo merupakan pembelajaran yang tidak memerlukan kelas formal untuk proses pembelajarannya.

\section{KESIMPULAN}

Pembelajaran dengan menggunakan teknologi atau biasa disebut dengan $e$ - learning saat ini banyak digunakan oleh tenaga pendidik karena terbatasnya pembelajaran tatap muka yang ada dikampus. Materi maupun tugas yang di posting oleh dosen dalam edmodo dapat diakses mahasiswa kapanpun dan dimanapun mereka berada. Dalam pelaksanaannya pembelajaran e-learning harus menggunakan sebuah media yang bisa menghubungkan antara dosen dan mah a siswa. Edmodo adalah salah satu media yang dapat digunakan. Pembelajaran geometri analitik dengan memanfaatkan edmodo sebagai media e-learning tentunya membantu kelancaran proses belajar mengajar di dalamnya. Sebagai media pembelajaran e-learning edmodo memiliki banyak kelebihan dibandingkan media pembelajaran yang lain. Kelebihan itu diantaranya adalah fitur- fitur yang ada juga sangat membantu dosen dalam membuat kelas virtual yang keadaannya dapat disesuaikan dengan kelas nyata. Seperti fitur penugasan yang bisa langsung dinilai oleh guru setelah batas waktu pengumpulan. Selain itu edmodo sangat mudah digunakan oleh guru, melalui edmodo guru juga bisa melakukan diskusi seperti di kelas nyata. Namun adapula sisi negatifnya tetapi dosen harus pintar untuk meniadakan hal negatif tersebut. Kelemahannya kurangnya interaksi sosial antar individu apabila terlalu sering memanfaatkan media tersebut, media pembelajaran edmodo sangat bergantung dengan koneksi internet.

Namun sisi negatif itu tidak seberapa apabila dibandingkan dengan sisi positifnya. Banyak sekali kemudahan yang dapat kita jumpai melalui pemanfaatan media tersebut. Diantaranya mempermudah proses pembelajaran karena proses belajar mengajar tidak harus selalu dilaksanakan di dalam ruang kelas.

\section{REFERENSI}

$\begin{array}{rrr}\text { Ainiyah, Z. } & \text { (2015). Penggunaan } \\ \text { Edmodo } & \text { sebagai } & \text { Media }\end{array}$


Pembelajaran Online pada Mata Pelajaran Otomatisasi Perkantoran di SMKN 1 Surabaya. Tersedia: http://ejournal.unesa.ac.id/article/1 6278/55/article.pdf. [10 November 2016]

Ansari, B.I. (2003). Menumbuh Kembangkan Kemampuan Pemahaman dan Komunikasi Matematis Siswa SMU malalui Strategi Think-Talk-Write. Disertasi Doktor pada PPS UPI. Bandung: Tidak Diterbitkan.

A. Witherspoon. (2011).

Edmodo...A learning

Management System.

Available:

http://www.plugintotechnol ogy.com/2011/01/edmodoa -learning-managementsystem.html

Creswell, J. W. (2010). Research Design Pendekatan Kualitatif, Kuantitatif dan Mixed.

Yogyakarta: Pustaka Pelajar

Dwiharja,

L.M.

(2015)

Memanfaatkan Edmodo sebagai Media Pembelajaran Akuntansi. [Online].

Tersedia:http://eprints.uny.ac.id/21 919/1/32\%20Laksmi\%20Mahendr ati\%20Dwiharja.pdf.

November 2016]

Nurita Putranti. (2013). Cara Membuat Media Pembelajaran Online Menggunakan Edmodo. Jurnal Pendidikan Informatika dan Sains, 2(2).Hlm. 141.

Rismayanti, A (2012). Mengenal lebih Dekat Edmodo sebagai Media E-learning dan Kolaborasi [on line]. Tersedia https://www.google.com/\#q =mengenal+lebih+dekat+e dmodo+sebagai+media+Elearning $+\% .09$ dan +kolaborasi. [19 November 2015].

Sugiyono. 2012. Metode Penelitian Kuantitatif Kualitatif \& RND. Bandung: Alfabeta

Zwang, J. 2010. Edmodo:A Free, Secure, SocialNetworking Site For School.

(Online),(http://www.eschoolnews .com/2010/12/15/edmodo-a-freesecure-social networkingsiteforschool/. Diakses 8 Desember 2016) 